\title{
Ectopic Parathormone Secretion Syndrome
}

National Cancer Institute

\section{Source}

National Cancer Institute. Ectopic Parathormone Secretion Syndrome. NCI Thesaurus.

Code C6790.

A syndrome characterized by abnormal secretion of parathyroid hormone in conjunction with neoplastic growth occurring anywhere in the body. 